\title{
Art Therapy Sebagai Penyaluran Emosi Anak
}

\author{
Siti Azizi Fauziyyah ${ }^{1 *}$, Ifdil Ifdil ${ }^{2}$, Yola Eka Putri ${ }^{1}$ \\ Indonesian Institute for Counseling, Education and Theraphy, Padang, Indonesia \\ Bimbingan dan Konseling, Universitas Negeri Padang, Indonesia \\ *) Correspondence Author address e-mail: azizifauziyyah@gmail.com
}

\begin{abstract}
Dalam undang-undang perlindungan anak pada tahun 2012 mengatakan bahwa anak merupakan generasi muda penerus cita-cita perjuangan bangsa yang memiliki peran penting dalam menjamin kelangsungan negara dan juga eksistensi bangsa ini. Dikarenakan hal ini tentu nya anak diharuskan berkembang secara optimal, baik secara fisik, mental serta sosial serta berakhlak mulia dan sejahtera kehidupannya. Dengan perkembangan emosi anak anak berbeda dan berkembang dengan pengalamanya serta hal diatas juga dapat menimbulkan permasalahan yang berbeda terkait. Emosi pada anak ibarat bom waktu yang ketika dibiarkan akan meledak dan jika demikian maka anak akan kehilangan pengendalian emosinnya. Oleh karena itu anak memerlukan wadah untuk penyaluran emosinya, seperti bermusik, olahraga, bermain, serta menggambar. Kegiatan menggambar pada anak dipercaya sebagai salah satu bentuk penyaluran emosia yang efektif dan kegiatan menggambar juga dapat sebagai bentuk terapi yang membantu anak menyalurkan emosi dalam diri nya yang dipendamnya selama ini yang berada di alam bawah sadarnya. Kegiatan ini dinamakan art therapy yang mana anak menggambar sesuai dengan hal-hal yang ingin disampaikan nya, dan melalui menggambar ini juga diharapkan juga efektif dalam penyelesaiain masalah yang di hadapi anak.
\end{abstract}

Keywords: Art Therapy, efektivitas, anak

Article History: Received on 15/09/2020; Revised on 20/10/2020; Accepted on 12/11/2020; Published Online: 23/12/2020. distribution, and reproduction in any medium, provided the original work is properly cited. (22020 by author.

\section{PENDAhuluaN}

Kategori anak sekolah berada pada rentang usia 6-12 tahun, pada usia ini mulai memasuki lingkungan seolah sehingga hubungan dengan orang lain berkembang (Whaley L 1987). Dalam usia ini anak mulai memaknai segala hal yang terjadi pada dirinya, yang jika makna itu hal yang baik maka akan meningkatkan harga diri anak tersebut, namun ketika makna ini bukan sesuatu hal yang baik maka anak akan menjadi rendah diri dan menjadi pribadi yang tertutup (Ball, J.W., \& Bindler 2003).

Masa anak-anak dipenuhi dengan keceriaan, kebahagiaan naum sejak perkembangan zaman yang hari demia hari bertambah maju dan canggih, yang membuat perilaku anak juga berubah sehingga anak menyaji anak yang agresif, emosional (Mahardika 2017).

Marah merupakan suatu emosi yang frekuensi nya sering dialami, namun ketika marah sudah tidak dapat ditangani maka masalah dalam perilaku dan sifat agresif akan muncul yang 
menyebabakan banyak nya terjadi penyimpangan (alavinezhad, Mousavi, and Sohrabi 2014; Studer, Asher, and Coie 1991).

Emosi merupakan perasaan ketidaknyamanan psikologia dan fisik ketika merasa dalam keadaan terancam, bentuk emosi ini terdiri dari taku, stress, sedih, depresi, frustasi, sehingga timbulnya perilaku agrsif (Masruhah 2019).

Kata emosional tidak hanya berarti pada kemarahan, namun dicintai, dihargai, merasa aman, dan merasa kompeten merupakan termasuk dari emosional sendiri, dan hal ini juga sangat di butuhkan oleh anak. Anak pada usia prasekolah adalah masa anak-anak belajar menguasai dan mengeskpresikan segala hal yang dirasakannya.

Dikarenakan dikategori anak-anak, anak memerlukan perhatian lebih dalam pengontrolan emosinya agar emosi tetap stabil dan menghindari perilaku emosi-emosi yang tidak diinginkan. Masalah akan timbul jika anak kehilangan kontrol terhadap emosi nya, dalam pengkategorian emosi ada empat gangguan emosi seperti ketidak mampuan anak dalam menunjukan tingkah laku yang sesuai situasi yang dihadapinya, ketidakmampuan anak dalam membangun hubungan pertemanan dengan teman-temannya, merasa depredi atau cemas yang berlebihan dengan faktor yang sangat kecil, merasa sakit perut ketika disuruh maju kedean kelas, dan lain sebagainya (Muthmainnah 2017). Anak sebagain besar memiiki perkembangan yang baik namun tidak memiliki keterampilan secara verbal untuk menyatakan apa yang dirasakan nya secara akurat (Kalkman and Naumburg 1947).

Untuk itu anak perlu tempat penyaluran emosi nya agar tidak meledak dikarenakan emosi yang di pendam anak ibarat bom waktu yang tidak tau kapan meledaknya. Emosi dapat disalurkan salah satu nya dengan melakukan terapi yang menyenangkan.

Setiap kali anak mengalami permasalahan dalam hal emosional seperti cepat tersinggung, cepat marah, trauma bahkan tantrum ini adalah bentuk tidak tersalurkan nya emosi anak dengan baik. Hal ini dapat di kurangi dengan terapi, terapi yang menyenangkan oleh anak dan anak merasa nyaman dalam proses ini. Bentuk terapi ini adalah art therapy.

Dalam (Meshcheryakova 2012) mengatakan bahwa seni dapat sebagai bentuk pengasuhan diri yang digunakan anak untuk menyenangkan diri nya dari perasaan tidak aman menjadi aman yang mereka sedang hadapi.

Dalam hal ini adalah seolah bermain dengan alat-alat yang diinginkan nya dan melakukan proses terapi dengan menyenangkan seperti menggambar, melukis, memahat, dan bentuk penyaluran emosi nya ini menghasilkan karya seni yang kreatif, ekspresif dan juga menyanangkan (Muthmainnah 2017).

Mengekspresikan emosi dengan menggambar simbol, bentuk tertentu adalah bentuk metafora kemarahan yang selama ini secara tidak dasar di pendam oleh anak dan juga art therapy ini anak melakukan prosedur menggambar, yang menceritakan hal yang membuat mereka bahagia, sedih, meraa tidak aman melalui gambar, coretan, warna tersebut (Morrison 2017).

Dalam sesi art therapy ini dapat digunakan oleh anak-anak dikarenakan anak-anak umumnya menyukai menggambar dan secara tidak lansung anak akan menggambar pengalaman mereka, tujuan mereka, emosi dan pikiran negatif anak sehingga art therapy dipercaya efektif dalam penyaluran emosi. (Argyle and Bolton 2005).

Hal yang sama juga dinyatakan oleh Muharan dan Warti bahwa menggambar adalah kegiatan yang disenangi anak-anak karena anak dapat bermain dengan warna sesuai dengan kemauan nya, terlebih lagi hakikat dari menggambar ini adalah penyajian ilusi optik atau pemindaian hal nyata menjadi bentuk dua dimensi (Muharam \& Sundaryati 2010). 
Gambar yang dihasilkan selama proses art therapy ini bisa menjelaskan secara rinci atau hanya gambaran kasar dar apa yang dialami anak. Namun penyelesaian masalah tidak selalu menghasilkan karya seni yan baik, namun proses anak dalam menggambar tersebut adalah proses yang membantu penyaluran emosi anak secara visual (Morrison 2017).

Dalam sesi art therapy dapat mengurangi sebagian besar emosi yang dirasakan anak, sehingga dapat meningkatkan hal-hal positif seperti kepercayaan diri, harga diri, dan meningkatkan kognitif anak seperti muculnya ide-ide yang selama ini terpendam tentang diri nya, peningkatan cara interaksi dengan lingkungan nya dan secara tidak langsung juga meningkatkan cara anak mengamati dan menganalisa sendiri keadaanya sendiri dan lingkungannya. (Case and Dalley 2003).

Manfaat dari melakukan art therapy ini adalah (1) mengatasi hilang kontrol perasaan, dengan saat art threapy berjalan dengan kegiatan memotong kertas, menempel stiker; (2) meningkatkan ketenagan dan penguasaan diri nya; (3) mehilangkan pemikiran bahwa kita hanya senidri; (4) terapi ini menghasilkan produk yang memiliki makna yang kreatif dan ekspresif (Malchiodi 1999).

Sehingga dari penjelasan diatas emosi anak yang terpendam dapat secara efektif disalurkan melalui kegiatan terapi seperti art therapy dan menilai dari karya yang dihasilkan anak untuk mengetahui apa yang dirasakan oleh anak.

\section{Pembahasan}

Art therapy dikenal sebagai terapi kontemporer yang memiliki latar belakang nilai seni yang ha tersebut menjadi pembeda tersendiri dengan metode terapi lain, dikarenakan melalui seni dipercaya dapat memhami diri lebih baik lagi (Hussain 2010).

Art therapy adalah bentuk psikoterapi yang dalam proses nya memanfaatkan media seni sebagai wada ekspresi dan komunikasi utama. Dalam art therapy ini menggunakan diagnostik sebagai alat analisis masalah yang emosional kemudia diamati dan dihubungkan dengan teori psikoterapi dan berbagai bentuk penunjang lainnya. (Regev and Cohen-Yatziv 2018).

Edith Kramer sebagai pelopor dari art therapy ini mengatakan seni adalah bagian dari hasil karya pengalam manudia dan ketika manusia tersebut tidak dapat mengakses pengalaman kreatif maka akan timbul masalah maka dari itu perlu wadah untuk penyalurannya. (Dye and Dye 2018).

Art therapy dianggap sebagai salah satu terapi yang efektif dalam menangani emosi anakanak dalam beberapa tahun terakhir, salah satu bentuk art therapy nya adalah terapi menggambar dan melukis (Koolaee et al. 2016). Melukis memiliki titik fokus dalam menggambar yang sangat memungkin dalam gambar tersebut dapat hal-hal yang ingin disampaikan dan di ekspresikan secara non verbal. (Dadsetan P 2005).

Anak cenderung agresif terhadap orang lain dan akan menghindari tempat-tempat yang memiliki memori buruk untuknya. Dengan adanya art therapy ini diyakini sebagai jembatan untuk mengetahui hal tersebut pada anak dan sangat efektif dengan hanya menggunakan alat seperti pensil, krayon, spidol atau cat yang dalam prosesnya anak akan menyalurkan emosinya, dan menyembuhkan dan mengatasi masalahya secara langsung (Morrison 2017).

Art therapy sangat membantu dalam anak-anak mengungkap emosi nya dikarenakan dapat mewakili perasaan anak yan tidak dapat ditunjukan melalui verbal / kata-kata (Durualp and Altay 2012; Perrin, Smith, and Yule 2000). Dalam Katza et al melukis dapat ditafsirkan sebagai bahasa 
untuk mengekspresikan emosi agresivitas karena anak-anak cenderung memiliki kosa kata yang terbatas (Djiwandono 2005).

Sehingga dalam mengekspresikan pengalaman emosinya sehingga kegiatan melukis dapat membantu hal itu (Katz and Hamama 2013) . Anak akan menggambar apa yang dilakukan, diamati, dirasakan yang secara tidak langsung tersalur dengan emosi yang dirasakan nya melalui tindakan coping (Durualp and Altay 2012).

Terlebih lagi kegiatan ini adala metode paling aman untuk meyalurkan emosi apa pun seperti kemarahan, kebenciam, penolakan, frustasi, perasaan terluka karena penyiksaan, tantrum, rasa malu, mengasingkan diri agar terbebaskan anak dari emosi tersebut (Djiwandono 2005).

Kegiatan menggambar juga merupakan bagian dari kegiatan art therapy untuk mendiagnosis dan menganalisa perilaku agresif pada anak (Behpazoh A 2002). Penelitian terdahulu juga mengatakan kefektivan art therapy dalam meningkatkan kinerja anak, kreativitas, kesadaran diri, dan hubungan dengan teman sebaya sebagai hasil keberhasilan dalam penyaluran emosi (STEINHARDT 1995).

Khadar et al mengatakan art therapy merupakan kegiatan seni melukis dan menggambar sebagai upaya pengurangan gejala perilaku menyimpang pada anak (Khadar, Babapour, and Sabourimoghaddam 2013). Dan juga dapat membangkitkan pikiran positif dengan berkurangnya sifat mengeluh (Nainis 2008).

Tidak hanya hasil karya, namun tujuan dari art therapy ini adalah memperoleh kebabasan dalam berkomunikasi yang berbentuk artistik (Psikologi et al. 2016). Dalam penelitia terdahulu art therapy adalah bentuk dari kegiatan psikologi dalam mengatasi kecemasan ataupun trauma pada kasus kekerasan. Sehingga dapat disimpulakan proses pembuatan kreasi seni ini dapat mengembangkan kemampuan coping (Case and Dalley 2003).

Dan diharapkan melalui proses art therapy ini sendiri dapat membantu mengenali individu dalam mengenali suara alam bawah sadar, sehinga termotivasi untuk menyembuhkan nya dengan art therapy ini, dan menyalurkan pikiran dan perasaan negatif melalui karya seni (Djiwandono 2005).

Dalam Chambala mengatakan art therapy memiliki kekuatan mengubah posisi kecemasan menjadi suatu karya yang kreatif sebagai bentuk penyaluran ekspresi diri dan mengeksplorasi diri (Chambala 2008). Dikarenakan melalui aktivitas ini anak akan melepaskan segala emosi nya, mengekpresikan diri melalui cara menggambar dan mengkomunikasikannya secara non verbal (Guex 1994).

Proses yang terjadi penyaluran emosi ini sendiri berbentuk pengalaman yang menjadi gambar atau lukisan atau aktivitas artistik lainya yang hal ini di kembangkan oleh otak yang diaplikasikan oleh gerak tubuh. Sehingga tubuh akan memberikan sinyal yang sama di kehidupan nyata seperti pembuatan gambar berhubungan dengan peristiwa yang terjadi ketika itu atau emosi dan kondisi yang ada dalam pikiran ketika hal tersebut terjadi (Malchiodi 2001).

Dalam penelitian yang dilakukan oleh Damaisio dan Baron juga menarik kesimpulan hal yang sama dengan mengatakan kaitan dalam proses pembuatan gambar dengan proses penyaluran emosi dan pikiran sangat berhubungan, mulai dari proses menggambar, melihat respon fisologis tubuh setelah dan sebelum melakukan art therapy (Psikologi et al. 2016).

Art therapy dapat dikatakan efektif karena ketika menggambar neuroscience juga berkembang, dikarenakan ketika menggambar akan mengaktifkan visual cortex pada otak yang merupakan kegiatan menyalin hal yang tampak nyata menjadi sebuah gambaran diatas kertas (Malchiodi 2003). 
Hal ini juga diperkuat dengan penyataan Ball yang mengakatakan art therapy membantu klien dalam mengatur perasaan nya (Ball 2002). Serta anak dapat merefleksi diri dengan konselor melalui seni. Terapi ini sangat efektif untuk menyalurkan, menertibkan, mengekspresikan pengalaman batin yang terasa dilaur kemampuan untuk mengungkapkannya (Ball 2002; Rubin 2005; Ulman 2001).

\section{SIMPULAN}

Anak memerlukan perhatian lebih dalam pengontrolan emosinya agar emosi tetap stabil dan menghindari perilaku emosi-emosi yang tidak diinginkan. Masalah akan timbul jika anak kehilangan kontrol terhadap emosi nya, dalam pengkategorian emosi ada empat gangguan emosi seperti ketidak mampuan anak dalam menunjukan tingkah laku yang sesuai situasi yang dihadapinya. Hal ini dapat diatasi dengan menyalurkan emosi nya dengan kegiatan positif, dan yang paling efektif untuk anak adalah menggambar dan melukis, dan hal ini termasuk dalam kegiatan terapi yaitu art therapy yang membantu anak menyalurkan emosinya, trauma, dan halhal yang tidak tersampaikan melalui kegiatan dalam art therapy.

\section{REFERENSI}

Alavinezhad, Ramin, Masoumeh Mousavi, and Nadereh Sohrabi. 2014. "Effects of Art Therapy on Anger and Self-Esteem in Aggressive Children." Procedia - Social and Behavioral Sciences 113:111-17.

Argyle, Elaine, and Gillie Bolton. 2005. "Art in the Community for Potentially Vulnerable Mental Health Groups." Health Education 105(5):340-54.

Ball, J.W., \& Bindler, R. .. 2003. Pediatric Nursing: Caring for Children. 3rd ed. New Jersey: Prentice Hall.

Ball, Barbara. 2002. "Moments of Change in the Art Therapy Process." Arts in Psychotherapy 29(2):79-92.

Behpazoh A, Nori F. 2002. "Effectiveness of Painting Therapy on Reducing of Aggressive Problem among Mental Retard Students." J Psychol Educat 32(2):155-70.

Case, Caroline, and Tessa Dalley. 2003. The Handbook of Art Therapy. New York: Guilford Press.

Chambala, A. 2008. "Anxiety and Art The- Rapy: Treatment in the Public Eye." Journal of Art Therapy Assocation 25(4):187-89.

Dadsetan P. 2005. “Evaluation of Child's Personality Based on Graphical Tests. 4th Ed." Tehran: Roshd 1-11.

Djiwandono, S. E. W. 2005. “Konseling Dan Terapi Dengan Anak Dan Orangtua." Jakarta: Gramedia.

Durualp, Ender, and Naime Altay. 2012. "A Comparison of Emotional Indicators and Depressive Symptom Levels of School-Age Children With and Without Cancer." Journal of Pediatric Oncology Nursing 29(4):232-39.

Dye, Meagan, and Meagan Paige Dye. 2018. "Evaluating the Benefits of Art Therapy Interventions with Grieving Children." Educational Specialist 129.

Guex, P. 1994. An Introduction to Psycho- Oncology. New York: Routledge.

Hussain, Sadia. 2010. "Art Therapy for Children Who Have Survived Disaster." Virtual Mentor 12(9):750-53.

Kalkman, Marion E., and Margaret Naumburg. 1947. Studies of the "Free" Art Expression of Behavior Problem Children and Adolescents As a Means of Diagnosis and Therapy. Vol. 47. New York: Teachers College Press, Teachers College, Columbia University.

Katz, Carmit, and Liat Hamama. 2013. “'Draw Me Everything That Happened to You': Exploring 
Children's Drawings of Sexual Abuse." Children and Youth Services Review 35(5):877-82.

Khadar, Mojtaba Gholamzade, Jalil Babapour, and Hassan Sabourimoghaddam. 2013. "The Effect of Art Therapy Based on Painting Therapy in Reducing Symptoms of Oppositional Defiant Disorder (ODD) in Elementary School Boys." Procedia - Social and Behavioral Sciences 84:187278.

Koolaee, Anahita Khodabakhshi, Roza Vazifehdar, Farshad Bahari, and Mohammad esmaeil Akbari. 2016. "Impact of Painting Therapy on Aggression and Anxiety of Children with Cancer." Caspian Journal of Pediatrics 2(2):135-41.

Mahardika, Bagus. 2017. "Implementasi Metode Art Therapy.” Jurnal Kependidikan 114-25.

Malchiodi, C. .. 1999. Medical Children Art Therapy. Philadelphia: Jessica Kingsley.

Malchiodi, C. A. 2001. "Using Drawing as Intervention with Traumatized Children." Trauma and Loss: Research and Intervention 1(1).

Malchiodi, C. A. 2003. Handbook of Art Therapy. New York: Guilford Press.

Masruhah, Ummahatul. 2019. Efektivitas Kegiatan Menggambar (Modifikasi Art Therapy) Untuk Mereduksi Stres Akademik Siswa Kelas Xii Sma Negeri 1 Pati.

Meshcheryakova, Ksenia. 2012. "Art Therapy with Orphaned Children: Dynamics of Early Relational Trauma and Repetition Compulsion." Art Therapy 29(2):50-59.

Morrison, Alexa. 2017. "The Benefits of Art Therapy with Children Affected by Acute Trauma."

Muharam \& Sundaryati. 2010. Pendidikan Kesenian II Seni Rupa. Jakarta: Depdikbud Dirjen Dikti.

Muthmainnah, -. 2017. "Peranan Terapi Menggambar Sebagai Katarsis Emosi Anak." Jurnal Pendidikan Anak 4(1):524-29.

Nainis, Nancy A. 2008. "Approaches to Art Therapy for Cancer Inpatients: Research and Practice Considerations." Art Therapy 25(3):115-21.

Perrin, Sean, Patrick Smith, and William Yule. 2000. "Practitioner Review: The Assessment and Treatment of Post-Traumatic Stress Disorder in Children and Adolescents." Journal of Child Psychology and Psychiatry and Allied Disciplines 41(3):277-89.

Psikologi, Fakultas, Universitas Gadjah Mada, Fakultas Psikologi, and Universitas Gadjah Mada. 2016. "Kajian Teoritis Pengaruh Art Therapy Dalam Mengurangi Kecemasan Pada Penderita." 18(1):29-35.

Regev, Dafna, and Liat Cohen-Yatziv. 2018. "Effectiveness of Art Therapy with Adult Clients in 2018-What Progress Has Been Made?" Frontiers in Psychology 9(AUG).

Rubin, Judith Aron. 2005. Child Art Therapy. Vol. 4. Hoboken, NJ: Wiley-Blackwell.

STEINHARDT, L. 1995. "Long-Term Creative Therapy With a Borderline Psychotic Boy." American Journal of Art Therapy 34(2):43-49.

Studer, Marlena M., Steven R. Asher, and John D. Coie. 1991. Peer Rejection in Childhood. Vol. 20. New York.

Ulman, Elinor. 2001. "Art Therapy: Problems of Definition." Art Therapy 40(1):16-24.

Whaley L, Wong DL. 1987. Wong's Nursing Care of Infants and Children. Missaouri: Mosby-Elsevier. 